\title{
RAD51 and XRCC3 Polymorphisms Are Associated with Increased Risk of Prostate Cancer
}

\author{
Maria Nowacka-Zawisza $\mathbb{D}^{1},{ }^{1}$ Agata Raszkiewicz, ${ }^{1}$ Tomasz Kwasiborski, ${ }^{1}$ Ewa Forma, \\ Magdalena Bryś, ${ }^{1}$ Waldemar Różański, ${ }^{2}$ and Wanda M. Krajewska ${ }^{1}$ \\ ${ }^{1}$ Department of Cytobiochemistry, Faculty of Biology and Environmental Protection, University of Lodz, Lodz, Poland \\ ${ }^{2}$ Department of Urology 2, Faculty of Biomedical Sciences and Postgraduate Training, Medical University of Lodz, Lodz, Poland
}

Correspondence should be addressed to Maria Nowacka-Zawisza; nmary@interia.pl

Received 21 January 2019; Revised 14 March 2019; Accepted 31 March 2019; Published 2 May 2019

Guest Editor: Zhihua Kang

Copyright (C) 2019 Maria Nowacka-Zawisza et al. This is an open access article distributed under the Creative Commons Attribution License, which permits unrestricted use, distribution, and reproduction in any medium, provided the original work is properly cited.

Genetic polymorphisms in DNA repair genes may affect DNA repair efficiency and may contribute to the risk of developing cancer. The aim of our study was to investigate single nucleotide polymorphisms (SNPs) in RAD51 (rs2619679, rs2928140, and rs5030789) and XRCC3 (rs1799796) involved in DNA double-strand break repair and their relationship to prostate cancer. The study group included 99 men diagnosed with prostate cancer and 205 cancer-free controls. SNP genotyping was performed using the PCR-RFLP method. A significant association was detected between RAD51 rs5030789 polymorphism and XRCC3 rs1799796 polymorphism and an increased risk of prostate cancer. Our results indicate that $R A D 51$ and XRCC3 polymorphism may contribute to prostate cancer.

\section{Introduction}

Prostate cancer is the second most commonly occurring cancer and the fifth leading cause of cancer death in men with an estimated 1.3 million new cases and 359.000 associated deaths worldwide in 2018. It is the most frequently diagnosed cancer among men in over one-half of the countries of the world $[1,2]$. Prostate cancer is characterized by the highest dynamic of increase in the last decade, and in 2016, for the first time, it became the most common cancer among men in Poland [3]. This cancer is very rarely manifested before the age of 50, and more than half of patients at the time of diagnosis are at least 70 years old. Age-adjusted incidence rates of prostate cancer increased dramatically and this is largely because of the increased availability of screening for specific prostate antigen (PSA) in men without symptoms of the desease. PSA screening offers a potential benefit of reducing the chance of death from prostate cancer. However, the value of PSA screening is moderate. An increase in PSA over $4 \mathrm{ng} / \mathrm{ml}$ suggests cancer, but nearly $25 \%$ of men with elevated levels of PSA do not have cancer, and nearly $20 \%$ of patients with prostate cancer have normal serum PSA. Elevated PSA levels may be also associated with benign conditions such as inflammation and benign prostatic hypertrophy and procedures such as bladder catheterization, transrectal ultrasound, gland biopsy, cystoscopy, and transurethral endoscopy. The search for markers other than PSA, allowing for early diagnosis and prognosis of prostate cancer, seems to be justified $[3,4]$. The factors associated with an increased risk of prostate cancer include family burden, race, ethnicity, obesity, high fat diet, smoking, and exposure to androgens [2]. Germline and somatic mutations appeared to be well-established risk factors for primary and metastaic prostate cancer. In addition, genome-wide association studies (GWAS) have identified approximately 170 SNPs associated with the development of prostate cancer. Pathogenic variants of high and moderate penetrance genes, such as BRCA1 and BRCA2, mismatch repair genes, and $H O X B 13$ confer modest to high lifetime risk of prostate cancer. Some, such as $B R C A 2$, have emerging clinical relevance in the treatment and screening for prostate cancer [5-8].

The process of tumorigenesis occurs in the absence of efficient DNA repair systems and this may, among others, result from genetic variations in the genes involved in them. The most deleterious form of DNA damage is the double-strand break (DSB). In order to maintain genomic 
stability, double-strand breaks must be repaired by homologous recombination (HR) or nonhomologous end joining (NHEJ). Germline and somatic mutations in genes that promote homology-directed repair, especially $B R C A 1$ and $B R C A 2$, are frequently observed in several cancers, in particular, breast and ovary, but also prostate and other cancers. The critical biochemical function of BRCA2 in homology-directed repair is to promote RAD51 filament assembly onto ssDNA that arises from end resection. BRCA2 directly interacts with RAD51 at multiple sites to facilitate RAD51 filament assembly. BRCA2 is shown to regulate both the intracellular localization and DNA-binding ability of RAD51. Loss of these controls may be a key event leading to genomic instability and tumorigenesis $[9,10]$. The human $R A D 51$, located on chromosome 15q15.1, plays a crucial role in DNA double-strand break repair [11]. The protein encoded by this gene is a member of RAD51 protein family. RAD51 family members are highly similar to bacterial RecA and Saccharomyces cerevisiae Rad51 and are known to be involved in the homologous recombination and repair of DNA. RAD51 binds to single- and double-stranded DNA and exhibits DNA-dependent ATPase activity. RAD51 catalyzes the recognition of homology and strand exchange between homologous DNA partners to form a joint molecule between a processed DNA break and the repair template. RAD51 binds to single-stranded DNA in an ATP-dependent manner to form nucleoprotein filaments which are essential for the homology search and strand exchange. RAD51 plays a role in regulating mitochondrial DNA copy number under conditions of oxidative stress in the presence of RAD51C and XRCC3 and is also involved in interstrand cross-link repair. At the site of DNA damage nuclear foci containing BRCA1, BRCA2, and RAD51, together with other proteins engaged in homologous recombination, are forming. The protein that binds to RAD51 is XRCC3. This combination facilitates formation of the nucleoprotein filament that represents primary vector for both homologous and heterologous recombination [12-16].

As we have previously shown the rs1801320 polymorphism in RAD51 may contribute to prostate cancer susceptibility in Poland [17]. The purpose of the presented work was to investigate further selected single nucleotide polymorphisms (SNPs), i.e., rs2619679, rs2928140, and rs5030789 in RAD51 and rs1799796 in RAD51 paralog XRCC3 and their relationship to prostate cancer.

\section{Material and Methods}

2.1. Patients. The study group included 99 men with prostate adenocarcinoma and 205 sex- and age-matched cancer-free subjects with low $(<4 \mathrm{ng} / \mathrm{ml})$ levels of PSA as a control group. Peripheral blood samples from the patients with prostate adenocarcinoma were obtained from the Department of Urology 2, Medical University of Lodz, Poland. Peripheral blood samples from the control group were obtained from the Urological Department of the Provincial M. SklodowskaCurie Hospital in Zgierz, Poland. Table 1 presents clinicopathological characteristics of patients and the control group.
TABLE 1: Clinicopathological characteristics of studied material.

\begin{tabular}{|c|c|}
\hline & Parameter \\
\hline \multicolumn{2}{|c|}{ Control group $(n=205)$} \\
\hline \multicolumn{2}{|l|}{ Age } \\
\hline Range & $43-84$ \\
\hline Mean \pm SD & $63.33 \pm 9.28$ \\
\hline Median & 64 \\
\hline \multicolumn{2}{|c|}{$\overline{P S A T}(\mathrm{ng} / \mathrm{ml})$} \\
\hline Range & $0.004-3.94$ \\
\hline Mean \pm SD & $1.09 \pm 0.88$ \\
\hline Median & 0.95 \\
\hline \multicolumn{2}{|c|}{ Patients with prostate cancer $(\mathrm{n}=99)$} \\
\hline \multicolumn{2}{|l|}{ Age } \\
\hline Range & $49-85$ \\
\hline Mean \pm SD & $70.38 \pm 8.63$ \\
\hline Median & 71 \\
\hline \multicolumn{2}{|c|}{ PSAT $(n g / m l)$} \\
\hline Range & $4.01-1489.00$ \\
\hline Mean \pm SD & $59.17 \pm 184.59$ \\
\hline Median & 9.22 \\
\hline \multicolumn{2}{|c|}{ Free/total PSA (F/T PSA) } \\
\hline Range & $0.04-0.79$ \\
\hline Mean \pm SD & $0.19 \pm 0.15$ \\
\hline Median & 0.16 \\
\hline$<0.16$ & 48 \\
\hline$\geq 0.16$ & 51 \\
\hline \multicolumn{2}{|c|}{ PSA Density (PSAD, $n g / m l)$} \\
\hline Range & $0.07-56.4$ \\
\hline Mean \pm SD & $2.57 \pm 8.44$ \\
\hline Median & 0.28 \\
\hline$<0.28$ & 49 \\
\hline$\geq 0.28$ & 50 \\
\hline \multicolumn{2}{|c|}{ Prostate volume $(\mathrm{ml})$} \\
\hline Range & $20.7-191$ \\
\hline Mean \pm SD & $59.5 \pm 39.0$ \\
\hline Median & 48.2 \\
\hline$<48$ & 46 \\
\hline$\geq 48$ & 53 \\
\hline \multicolumn{2}{|c|}{ Gleason score } \\
\hline$<7$ & 28 \\
\hline$\geq 7$ & 71 \\
\hline \multicolumn{2}{|l|}{ Cancer stage } \\
\hline $\mathrm{T} 1-\mathrm{T} 2$ & 58 \\
\hline T3-T4 & 41 \\
\hline
\end{tabular}

2.2. DNA Isolation. DNA from peripheral blood was isolated by phenol extraction [18] or using AxyPrep Blood Genomic DNA Miniprep Kit (Axygen Biosciences) and stored in $70^{\circ} \mathrm{C}$. DNA preparations were subjected to spectrophotometric analysis (Biophotometer Eppendorf AG, Germany) by measuring absorbance at $260 \mathrm{~nm}$ and $280 \mathrm{~nm}$ to determine the quantity and quality of the isolated nucleic acid. The A260/A280 ratio was in the range 1.8-2.1. 
TABLE 2: Polymorphic sites in RAD51 and XRCC3 (according to NCBI).

\begin{tabular}{|c|c|c|c|c|}
\hline Gene & SNP & Other names & Chromosome & SNP position \\
\hline \multirow{4}{*}{ RAD51 } & \multirow[t]{2}{*}{ rs2619679 } & g.3879T >A & \multirow[t]{2}{*}{ 15: 40694039} & \multirow[t]{2}{*}{ Promoter } \\
\hline & & c. $-1285 \mathrm{~T}>\mathrm{A}$ & & \\
\hline & rs2928140 & $\begin{array}{l}\text { g. } 7995 \mathrm{G}>\mathrm{C}, \\
\text { c. }-2-602 \mathrm{G}>\mathrm{C}\end{array}$ & 15: 40698155 & Intron 1 \\
\hline & rs5030789 & $\begin{array}{l}\text { g. } 3997 \mathrm{~A}>\mathrm{G} \\
\text { c. }-1167 \mathrm{~A}>\mathrm{G}\end{array}$ & 15: 40694157 & Promoter \\
\hline XRCC3 & rs1799796 & $\begin{array}{c}\text { g. } 20897 \mathrm{~A}>\mathrm{G} \\
\text { c. } 562 \mathrm{~A}>\mathrm{G}\end{array}$ & 14: 103699590 & Intron 7 \\
\hline
\end{tabular}

2.3. Genotyping. Single nucleotide polymorphism (SNP) was determined by PCR-RFLP (polymerase chain reactionrestriction fragment length polymorphism). Tested SNPs are shown in the Table 2.

The primers for studied SNPs were as follows: (F) $5^{\prime}$ CCGTGCAGGCCTTATATGAT- $3^{\prime}$ and (R) $5^{\prime}$-AGATAAACCTGGCCAACGTG-3' for rs2619679; (F) $5^{\prime}$-GCTTCTGGCTATTTTCAAGT-3' and (R) $5^{\prime}$-TGAGGCAGGTAAATGGCTTC-3' for rs2928140; (F) $5^{\prime}$-CCGTGCAGGCCTTATATGAT- $3^{\prime}$ and (R) $5^{\prime}$-AGATAAACCTGGCCAACGTG-3' for rs5030789; (F) 5'-CCGCATCCTGGCTAAAAATA-3' and (R) $5^{\prime}$-CAGAGTATGGGCACTGTGAGC-3' for rs1799796. The primers were synthesized at Sigma-Aldrich ${ }^{\circledR}$. The polymerase chain reaction (PCR) was performed in an Applied Biosystems ${ }^{\circledR} 2720$ thermocycler in total volume of 10 $\mu \mathrm{l}$. The reaction mixture contained $10 \mathrm{ng}$ of genomic DNA; $0.2 \mu$ moles of primers (F) and (R); 3 HOT FIREPol ${ }^{\circledR}$ units of DNA polymerase $(5 \mathrm{U} / \mathrm{ml}) ; 1 \mathrm{mM}$ GeneAmp dNTPmix (10 $\mathrm{mM}) ; 2.5 \mathrm{mM}$ magnesium chloride (25 mM); and $1 \mathrm{x}$ Solis BioDyne buffer B1 (10x concentrated). The components of the PCR reaction mixture were from Solis BioDyne (Estonia) and Applied Biosystem (USA).

The temperature-time profile of PCR was as follows: PrePCR: $95^{\circ} \mathrm{C}$ for $12 \mathrm{~min}$; PCR (30 cycles): $95^{\circ} \mathrm{C}$ for $0.5 \mathrm{~min}, 63^{\circ} \mathrm{C}$ (rs2928140) or $64^{\circ} \mathrm{C}$ (for rs2619679 and rs1799796) or $65^{\circ} \mathrm{C}$ (rs5030789) for $0.5 \mathrm{~min}, 72^{\circ} \mathrm{C}$ for $1 \mathrm{~min}$; Post-PCR at $72^{\circ} \mathrm{C}$ for $5 \mathrm{~min}$.

The amplification products were digested with restriction enzymes: HinfI (rs2619679), EarI (rs2928140), NlaIII (rs5030789), or AluI (rs1799796) at $37^{\circ} \mathrm{C}$ for 16 hours. Enzyme inactivation lasted 20 minutes at $65^{\circ} \mathrm{C}$ for EarI and at $80^{\circ} \mathrm{C}$ for HinfI, NlaIII, and AluI. The enzymes came from New England BioLabs Inc. DNA fragments were separated in a $3 \%$ agarose gel with ethidium bromide for UV visualization. Electrophoresis was performed in 1x TBE buffer (10x TBE: 89 $\mathrm{mM}$ Tris, $89 \mathrm{mM}$ boric acid, 2 M EDTA pH 8.0) and 100V. Examples of the obtained restriction patterns are shown in Figure 1.

2.4. Statistical Analysis. The compatibility of the genotype distribution with the Hardy-Weinberg law in the control group and in study group was checked by the $\chi^{2}$ test. Significance of differences between the distribution of genotypes/alleles in the control and study group was assessed by the $\chi^{2}$ test. The risk of comorbidity of genotypes/alleles with the disease was assessed based on odds ratio (OR) together with a 95\% confidence interval. All results were considered statistically significant at $p$ values $<0.05$. Statistical calculations were made using spreadsheets available on the websites: quantpsy.org/chisq/chisq.htm and vassarstats.net/odds $2 \times 2 . h t m l$.

\section{Results}

Table 3 presents results of studied polymorphisms in RAD51 and XRCC3 using the PCR-RFLP method. The distribution of genotypes and alleles in the control group and in patients with prostate cancer was consistent with Hardy-Weinberg law $(p>0.05)$. Statistically significant differences were found in the distribution of genotypes and alleles for rs5030789 and rs1799796 polymorphism in RAD51 and XRCC3, respectively, between control group and prostate cancer patients.

The odds ratio (OR) analysis showed that rs5030789 polymorphism in RAD51 and rs1799796 polymorphism in XRCC3 are associated with susceptibility to prostate cancer (Table 4). The presence of the GG genotype in both polymorphic sites of $R A D 51$ and XRCC3 increases the risk of prostate cancer (OR $=2.782, p=0.038$ for rs5030789; OR $=1.986, p=0.041$ for rs1799796). Also, the presence of the $\mathrm{G}$ allele increases the risk of developing prostate cancer in both above polymorphisms $(\mathrm{OR}=1.571$ for $\mathrm{rs5030789}$ and $\mathrm{OR}=1.441$ for rs1799796, $p<0.05)$.

Because the polymorphism rs5030789 in RAD51 and polymorphism rs1799796 in XRCC3 increase the risk of prostate cancer, the correlation of these polymorphisms with age and clinicopathological characteristcs of prostate cancer patients was examined (Table 5). It was revealed that there is a relationship between rs1799796 polymorphism in XRCC3 and the age of patients over 71 years $(\mathrm{OR}=1.916, p=0.033)$ and Gleason score of cancer equal to or higher than $7(\mathrm{OR}=$ 2.373, $p=0.012$ ). No association was found with the level of PSAT, nor with rs5030789 in RAD51 nor rs1799796 in XRCC3.

\section{Discussion}

Prostate specific antigen (PSA) is a blood-based biomarker used for the detection and surveillance of prostate cancer. However, PSA levels can also be affected by benign prostatic hyperplasia $(\mathrm{BPH})$, local inflammation or infection, prostate volume, age, and genetic factors. In this regard, PSA seems to be an organ but not cancer specific biomarker [19]. Seeking the molecular mechanisms underlying prostate 


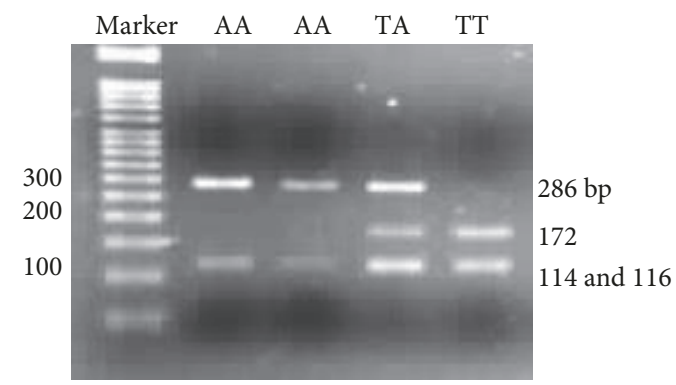

(a)

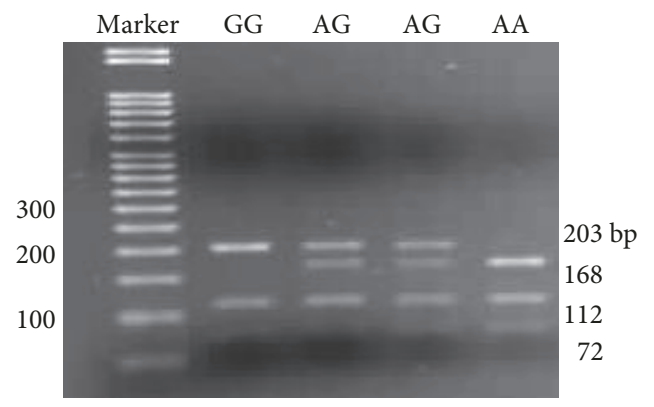

(c)

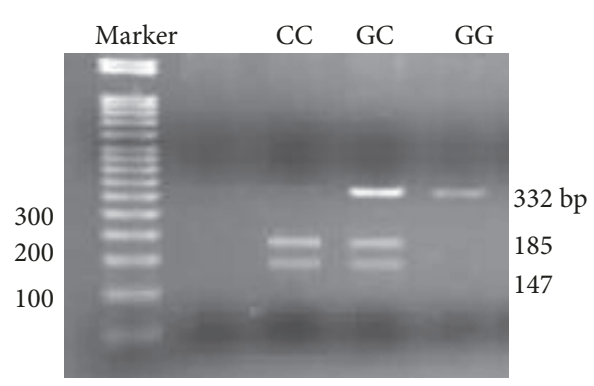

(b)

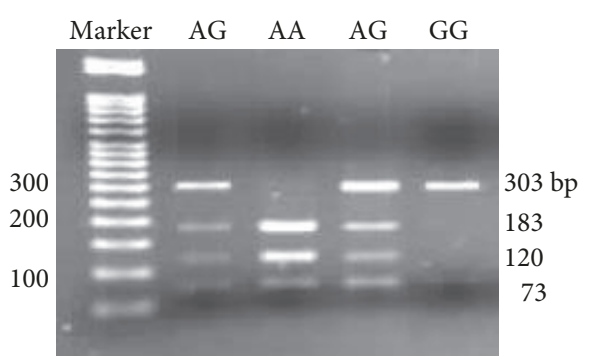

(d)

FIGURE 1: PCR-RFLP genotyping of (a) RAD51 rs2619679 polymorphism; (b) RAD51 rs2928140 polymorphism; (c) RAD51 rs5030789 polymorphism; (d) XRCC3 rs1799796 polymorphism.

TABLE 3: Distribution of genotypes and allele frequency of studied SNPs in RAD51 and XRCC3 in prostate cancer patients and control group.

\begin{tabular}{|c|c|c|c|c|}
\hline Gene & rs & Genotype/allele & Control group $(n=205)$ & Prostate cancer patients $(n=99)$ \\
\hline & & TT & 48 & 30 \\
\hline & & TA & 101 & 51 \\
\hline & & AA & 56 & 18 \\
\hline & rs2619679 & & $\chi^{2}=3.59, p=0.17$ & \\
\hline & & $\mathrm{T}$ & 197 & 111 \\
\hline & & A & 213 & 87 \\
\hline & & & $\chi^{2}=3.43, p=0.06$ & \\
\hline & & GG & 95 & 43 \\
\hline & & GC & 63 & 36 \\
\hline & & CC & 47 & 20 \\
\hline \multirow[t]{14}{*}{ RAD51 } & rs2928140 & & $\chi^{2}=1.00, p=0.61$ & \\
\hline & & G & 253 & 122 \\
\hline & & $\mathrm{C}$ & 157 & 76 \\
\hline & & & $\chi^{2}=0, p=1.00$ & \\
\hline & & AA & 29 & 7 \\
\hline & & AG & 106 & 45 \\
\hline & & GG & 70 & 47 \\
\hline & rs5030789 & & $\chi^{2}=6.43, p=0.04$ & \\
\hline & & A & 164 & 59 \\
\hline & & G & 246 & 139 \\
\hline & & & $\chi^{2}=5.98, p=0.01$ & \\
\hline & & AA & 77 & 28 \\
\hline & & AG & 92 & 45 \\
\hline & & GG & 36 & 26 \\
\hline \multirow[t]{4}{*}{ XRCC3 } & rs1799796 & & $\chi^{2}=4.15, p=0.13$ & \\
\hline & & A & 246 & 101 \\
\hline & & G & 164 & 97 \\
\hline & & & $\chi^{2}=4.40, p=0.04$ & \\
\hline
\end{tabular}


TABLE 4: Prostate cancer risk and RAD51 and XRCC3 polymorphism.

\begin{tabular}{|c|c|c|c|c|c|c|}
\hline Gene & rs & Genotype/allele & Control group $(\mathrm{n}=205)$ & Prostate cancer patients $(\mathrm{n}=99)$ & OR $(95 \% \mathrm{Cl})$ & $p$ value \\
\hline \multirow{15}{*}{ RAD51 } & \multirow{5}{*}{ rs2619679 } & TT & 48 & 30 & 1 (Ref.) & \\
\hline & & TA & 101 & 51 & $0.808(0.459-1.424)$ & 0.554 \\
\hline & & AA & 56 & 18 & $0.514(0.255-1.036)$ & 0.089 \\
\hline & & $\mathrm{T}$ & 197 & 111 & 1 (Ref.) & \\
\hline & & A & 213 & 87 & $0.725(0.515-1.020)$ & 0.077 \\
\hline & \multirow{5}{*}{ rs2928140 } & GG & 95 & 43 & 1 (Ref.) & \\
\hline & & GC & 63 & 36 & $1.262(0.732-2.178)$ & 0.484 \\
\hline & & $\mathrm{CC}$ & 47 & 20 & $0.940(0.498-1.775)$ & 0.841 \\
\hline & & G & 253 & 122 & 1 (Ref.) & \\
\hline & & $\mathrm{C}$ & 157 & 76 & $1.004(0.708-1.423)$ & 0.526 \\
\hline & \multirow{5}{*}{ rs5030789 } & AA & 29 & 7 & 1 (Ref.) & \\
\hline & & AG & 106 & 45 & $1.759(0.718-4.309)$ & 0.299 \\
\hline & & GG & 70 & 47 & $2.782(1.126-6.872)$ & 0.038 \\
\hline & & A & 164 & 59 & 1 (Ref.) & \\
\hline & & G & 246 & 139 & $1.571(1.093-2.228)$ & 0.018 \\
\hline \multirow{5}{*}{ XRCC3 } & \multirow{5}{*}{ rs1799796 } & $\mathrm{AA}$ & 77 & 28 & 1 (Ref.) & \\
\hline & & AG & 92 & 45 & $1.345(0.768-2.356)$ & 0.371 \\
\hline & & GG & 36 & 26 & $1.986(1.022-3.860)$ & 0.041 \\
\hline & & A & 246 & 101 & 1 (Ref.) & \\
\hline & & G & 164 & 97 & $1.441(1.024-2.027)$ & 0.044 \\
\hline
\end{tabular}

cancer, many mutations and polymorphisms of a single nucleotide have been identified, especially in DNA repair genes, which increase the risk of developing prostate cancer. Polymorphic genes of DNA repair are in great part included in low penetrance genes, which means that single gene product most often slightly affects the disease occurrence risk, but accumulation of changed alleles can have essential significance for its development. RAD51, which is a critical protein involved in the homologous recombination repair pathway, interacts with XRCC2, XRCC3, and other proteins to form a complex that is crucial for repairing the doublestrand breaks and maintaining chromosome stability $[12,16$, 20].

To our knowledge, genetic abnormalities in RAD51 paralogs, i.e., RAD51C and RAD51D, have been identified in prostate cancer, but not in RAD51 [5-10]. Our study has shown the importance of RAD51 and its paralog XRCC3 polymorphism in prostate cancer. Single nucleotide polymorphism within these genes may affect DNA double-strand break repair capacity, hence the increased susceptibility to neoplastic transformation. There is growing body of evidence which suggests that polymorphic variants of these genes have impact on developing different cancers. A metaanalysis conducted by Zeng et al. [11] suggests that RAD51 rs1801320 (135G/C) polymorphism is a risk factor for three common gynecological tumors, i.e., breast, endometrial, and ovarian cancers, and especially for endometrial cancer. AlZoubi et al. [21] in their studies demonstrated that the homozygous variant T172T (rs1803121) is significantly associated with breast cancer risk (OR 3.717, 95\% CI 2.283$6.052, p<0.0001$ ), while the heterozygous variant G135C (rs1801320) has no significant relationship with the risk of sporadic breast cancer (OR 1.598, 95\% CI 0.5638-4.528, $p$ $>0.05$ ). However, both variants homozygous T172T and heterozygous G135C together showed a significant association with sporadic breast cancer susceptibility. Michalska et al. [22] found that the polymorphism of RAD51 may be positively associated with the incidence of triple-negative breast carcinoma while Sekhar et al. [23] indicated that RAD51 135G > C substitution in the homozygous form (CC) increases the risk of breast cancer in an ethnic-specific manner. Söderlund et al. [24] suggest that RAD51 135G>C polymorphism predicts cyclophosphamide/methotrexate/5fluorouracil chemotherapy effect in early breast cancer.

Polymorphism of the RAD51 also seems to play a role in other types of cancer. In our previous study we found a significant relationship between $R A D 51$ polymorphism rs1801320 and an increased risk of prostate cancer [17]. It has been shown that subjects carrying RAD51 rs1801320 GC genotype also have an increased risk of glioblastoma (GC vs GG, $\chi(2)$ $=10.75$; OR 3.0087; $p=0.0010$ ). In addition, $R A D 51 \mathrm{rs} 1801320$ $\mathrm{C}$ allele increased the risk of developing glioblastoma also in combination with the XRCC1 rs25487 G allele and XRCC3 rs861539 C allele $(\chi(2)=6.558 ; p=0.0053)$ [25]. Trang et al. [26] showed that the combination of Helicobacter pylori infection and RAD51 G135C genotype of the host leads to an increased score for intestinal metaplasia. This suggests that $R A D 51 \mathrm{G} 135 \mathrm{C}$ may be an important predictor for gastric cancer of Helicobacter pylori-infected patients. Mucha et al. [27] study revealed a statistically significant association also between rs5030789 polymorphism in RAD51 and the risk of colorectal cancer. In turn in the case of rs2619679 polymorphism in $R A D 51$, it was shown that it does not correlate with the risk of head and neck cancer [28]. 
TABLE 5: Relationship between G allele for rs5030789 in RAD51 and rs1799796 in XRCC3 and clinicopathological characteristics of prostate cancer patients.

\begin{tabular}{|c|c|c|c|c|}
\hline \multirow{2}{*}{ Clinicopathological parameter } & \multicolumn{2}{|c|}{ rs5030789 } & \multicolumn{2}{|c|}{ rs1799796 } \\
\hline & $\mathrm{A}$ & $\mathrm{G}$ & $\mathrm{A}$ & G \\
\hline \multicolumn{5}{|l|}{ Age } \\
\hline$\leq 71$ & 35 & 67 & 60 & 42 \\
\hline \multirow[t]{3}{*}{$>71$} & 24 & 72 & 41 & 55 \\
\hline & \multicolumn{2}{|c|}{$\mathrm{OR}=1.567(0.846-2.902)$} & \multicolumn{2}{|c|}{$O R=1.916(1.089-3.371)$} \\
\hline & \multicolumn{2}{|c|}{$p=0.202$} & \multicolumn{2}{|c|}{$p=0.033$} \\
\hline \multicolumn{5}{|l|}{ PSAT $(\mathrm{ng} / \mathrm{ml})$} \\
\hline$<4-10$ & 34 & 68 & 53 & 49 \\
\hline \multirow[t]{3}{*}{$>10$} & 25 & 71 & 48 & 48 \\
\hline & \multicolumn{2}{|c|}{$\mathrm{OR}=1.420(0.768-2.624)$} & \multicolumn{2}{|c|}{$\mathrm{OR}=1.082(0.619-1.889)$} \\
\hline & \multicolumn{2}{|c|}{$p=0.335$} & \multicolumn{2}{|c|}{$p=0.887$} \\
\hline \multicolumn{5}{|l|}{ Free/total PSA (F/T PSA) } \\
\hline$<0.16$ & 25 & 71 & 44 & 52 \\
\hline \multirow[t]{3}{*}{$\geq 0.16$} & 34 & 68 & 57 & 45 \\
\hline & \multicolumn{2}{|c|}{$\mathrm{OR}=0.704(0.381-1.301)$} & \multicolumn{2}{|c|}{$\mathrm{OR}=0.668(0.381-1.170)$} \\
\hline & \multicolumn{2}{|c|}{$p=0.335$} & \multicolumn{2}{|c|}{$p=0.203$} \\
\hline \multicolumn{5}{|l|}{ PSA Density (PSAD, ng/ml) } \\
\hline$<0.28$ & 26 & 72 & 49 & 49 \\
\hline \multirow[t]{3}{*}{$\geq 0.28$} & 33 & 67 & 52 & 48 \\
\hline & \multicolumn{2}{|c|}{$\mathrm{OR}=0.733(0.397-1.352)$} & \multicolumn{2}{|c|}{$\mathrm{OR}=0.923(0.529-1.612)$} \\
\hline & \multicolumn{2}{|c|}{$p=0.399$} & \multicolumn{2}{|c|}{$p=0.888$} \\
\hline \multicolumn{5}{|l|}{ Prostate volume $(\mathrm{ml})$} \\
\hline$<48$ & 31 & 61 & 52 & 40 \\
\hline$\geq 48$ & 28 & 78 & 49 & 57 \\
\hline & & & & \\
\hline & & & & \\
\hline Gleason score & & & & \\
\hline$<7$ & 19 & 37 & 37 & 19 \\
\hline$\geq 7$ & 40 & 102 & 64 & 78 \\
\hline & & & & \\
\hline & & & & \\
\hline Cancer stage & & & & \\
\hline T1-T2 & 35 & 81 & 58 & 58 \\
\hline T3-T4 & 24 & 58 & 43 & 39 \\
\hline & & & & \\
\hline & & & & \\
\hline
\end{tabular}

Avadanei et al. [29] findings suggest that XRCC3 polymorphism in hepatocellular carcinoma may affect the aggressiveness of the tumor expressed by tumor grade. Statistically significant differences were shown for rs1799796 A>G and tumor grade, between wild type (AA) and heterozygote (AG) genotypes, and wild type (AA) and heterozygote and homozygote (AG and $\mathrm{GG}$ ) genotypes. The logistic regression analysis found an OR of rs1799796 polymorphism occurrence in hepatocellular carcinoma related to tumor grade. In the case of rs861539 C>T polymorphism, statistical analysis showed better survival only for the homozygote (TT) compared to the heterozygote (CT) genotype, and in the case of rs1799796 $\mathrm{A}>\mathrm{G}$ polymorphism, a longer survival for wild type (AA) compared to heterozygote (AG) and to heterozygote and homozygote (AG and GG) genotypes, respectively. The results presented by Ali et al. [30] suggest that the polymorphism rs1799794 in XRCC3 is strongly associated with the development of breast cancer in Saudi women while genotype and allele frequencies of rs861539 C>T and rs1799796 $\mathrm{A}>\mathrm{G}$ did not show a significant difference. However, the frequency of rs1799796 differed significantly in patients depending on the age of the diagnosis, tumor grade, and ER and HER2 status. The wild type A allele occurred more frequently in the ER- and HER2- group. It was also found that the presence of the polymorphism rs1799796 in XRCC3 may reduce the risk of oral premalignant lesions [31]. On the other hand, Mandal et al. [32] showed no significant association between rs1799796 and rs861539 polymorphism 
in $X R C C 3$ and the risk of prostate cancer. In the case of studies conducted by Mittal et al. [33], no direct relationship was found between the occurrence of rs1799796 polymorphism in XRCC 3 and the incidence of bladder cancer. In addition, the studied polymorphism seems to be not related to the incidence of nasopharyngeal cancer as well as head and neck cancer [27, 34]. However, a meta-analysis of 5302 cases of ovarian cancer compared to 8075 control cases revealed statistically significant correlation of rs1799794 and rs1799796 polymorphism in XRCC3 and an increased risk of developing ovarian cancer in Caucasians, Asian, and African population [35]. It is also worth pointing out that Vral et al. [36] have demonstrated the combined effect of polymorphisms in $R A D 51$ and XRCC 3 on breast cancer risk.

\section{Conclusion}

Our study showed that rs5030789 polymorphism in RAD51 and rs1799796 in XRCC3 are associated with the occurrence of prostate cancer in Polish men. We have demonstrated correlation between the rs1799796 polymorphism in XRCC3 and the age of patients over 71 years and Gleason score of tumor higher than 7. Our findings indicate the importance of RAD51 and XRCC3 polymorphisms in the development of prostate cancer. Based on the results presented, we suggest considering genetic testing for RAD51 and XRCC3 to identify those men who have DNA repair deficiency and who have not responded to standard treatment.

\section{Data Availability}

The data used to support the findings of the study are included within article.

\section{Ethical Approval}

The study was conducted in accordance with the ethical standards of the 1975 Helsinki Declaration and its later amendments and approved by institutional ethics committees (University of Lodz, Poland, KBBN-UL/25/2012; Medical University of Lodz, Poland, RNN/59/089/KE).

\section{Consent}

Informed consent was obtained from the patients.

\section{Conflicts of Interest}

The authors declare that there are no conflicts of interest.

\section{Authors' Contributions}

M. Nowacka-Zawisza, A. Raszkiewicz, T. Kwasiborski, and E. Forma performed the experiments. M. Nowacka-Zawisza analyzed data. M. Nowacka-Zawisza, M. Bryś, and W. Różański collected study samples. M. Nowacka-Zawisza and W. M. Krajewska designed the research study and wrote the paper.

\section{References}

[1] F. Bray, J. Ferlay, I. Soerjomataram, R. L. Siegel, L. A. Torre, and A. Jemal, "Global cancer statistics 2018: globocan estimates of incidence and mortality worldwide for 36 cancers in 185 countries," CA: A Cancer Journal for Clinicians, vol. 68, no. 6 , pp. 394-424, 2018.

[2] C. H. Pernar, E. M. Ebot, K. M. Wilson, and L. A. Mucci, "The epidemiology of prostate cancer," Cold Spring Harbor Perspectives in Medicine, vol. 8, no. 12, Article ID a030361, 2018.

[3] U. Wojciechowska, K. Czaderny, A. Ciuba, P. Olasek, and J. Didkowska, "Cancer in Poland in 2016," The Maria SklodowskaCurie Memorial Cancer Center and Institute of Oncology, Polish National Cancer Registry, 2018, Warsaw, Poland, http://onkologia.org.pl/publikacje/.

[4] H. E. Taitt, "Global trends and prostate cancer: a review of incidence, detection, and mortality as influenced by race, ethnicity, and geographic location," American Journal of Men's Health, vol. 12, no. 6, pp. 1807-1823, 2018.

[5] R. Eeles and H. N. Raghallaigh, "Men with a susceptibility to prostate cancer and the role of genetic based screening," Translational Andrology and Urology, vol. 7, no. 1, pp. 61-69, 2018.

[6] S.-H. Tan, G. Petrovics, and S. Srivastava, "Prostate cancer genomics: Recent advances and the prevailing underrepresentation from racial and ethnic minorities," International Journal of Molecular Sciences, vol. 19, no. 4, 2018.

[7] H. H. Cheng, C. C. Pritchard, B. Montgomery, D. W. Lin, and P. S. Nelson, "Prostate cancer screening in a new era of genetics," Clinical Genitourinary Cancer, vol. 15, no. 6, pp. 625-628, 2017.

[8] D. Robinson, E. M. Van Allen, Y.-M. Wu et al. et al., "Integrative Clinical Genomics of Advanced Prostate Cancer," Cell, vol. 161, no. 5, pp. 1215-1228, 2015.

[9] C. Chen, W. Feng, P. X. Lim, E. M. Kass, and M. Jasin, "Homology-directed repair and the role of BRCA1, BRCA2, and related proteins in genome integrity and cancer," Annual Review of Cancer Biology, vol. 2, no. 1, pp. 313-336, 2018.

[10] B. R. Potugari, J. M. Engel, and A. A. Onitilo, "Metastatic prostate cancer in a RAD51C mutation carrier," Clinical Medicine and Research, vol. 16, no. 3-4, pp. 69-72, 2018.

[11] X. Zeng, Y. Zhang, L. Yang et al., "Association between RAD51 135 G/C polymorphism and risk of 3 common gynecological cancers: a meta-analysis," Medicine, vol. 97, no. 26, p. el1251, 2018.

[12] W. D. Wright, S. S. Shah, and W.-D. Heyer, "Homologous recombination and the repair of DNA double-strand breaks," Journal of Biological Chemistry, vol. 293, no. 27, pp. 10524-10535, 2018.

[13] S. Inano, K. Sato, Y. Katsuki et al., "RFWD3-mediated ubiquitination promotes timely removal of both RPA and RAD51 from DNA damage sites to facilitate homologous recombination," Molecular Cell, vol. 66, no. 5, pp. 622-634.e8, 2017.

[14] N. Ameziane, P. May, A. Haitjema et al., "A novel Fanconi anaemia subtype associated with a dominant-negative mutation in RAD51," Nature Communications, vol. 18, no. 6, p. 8829, 2015.

[15] A. T. Wang, T. Kim, J. E. Wagner et al., "A dominant mutation in human RAD51 reveals its function in DNA interstrand crosslink repair independent of homologous recombination," Molecular Cell, vol. 59, no. 3, pp. 478-490, 2015.

[16] M. A. Brenneman, B. M. Wagener, C. A. Miller, C. Allen, and J. A. Nickoloff, "XRCC3 controls the fidelity of homologous 
recombination: Roles for XRCC3 in late stages of recombination," Molecular Cell, vol. 10, no. 2, pp. 387-395, 2002.

[17] M. Nowacka-Zawisza, E. Wiśnik, A. Wasilewski et al., "Polymorphisms of Homologous recombination RAD51, RAD51B, XRCC2, and XRCC3 genes and the risk of prostate cancer," Analytical Cellular Pathology, vol. 2015, Article ID 828646, 9 pages, 2015.

[18] J. Sambrook and D. W. Russell, Molecular Cloning: A Laboratory Manual, Cold Spring Harbor Laboratory Press, Cold Spring Harbor, NY, USA, 2001.

[19] T. J. Hoffmann, M. N. Passarelli, R. E. Graff et al., "Genome-wide association study of prostate-specific antigen levels identifies novel loci independent of prostate cancer," Nature Communications, vol. 8, p. 14248, 2017.

[20] Z. Qureshi, I. Mahjabeen, R. M. Baig, and M. A. Kayani, "Correlation between selected XRCC2, XRCC3 and RAD51 gene polymorphisms and primary breast cancer in women in Pakistan," Asian Pacific Journal of Cancer Prevention, vol. 15, no. 23, pp. 10225-10229, 2014.

[21] M. S. Al-Zoubi, C. M. Mazzanti, K. Zavaglia et al., "Homozygous T172T and heterozygous G135C variants of homologous recombination repairing Protein RAD51 are related to sporadic breast cancer susceptibility," Biochemical Genetics, vol. 54, no. 1, pp. 83-94, 2016.

[22] M. M. Michalska, D. Samulak, H. Romanowicz, and B. Smolarz, "Single nucleotide polymorphisms (SNPs) of RAD51-G172T and XRCC2-41657C/T homologous recombination repair genes and the risk of triple- negative breast cancer in polish women," Pathology \& Oncology Research, vol. 21, no. 4, pp. 935-940, 2015.

[23] D. Sekhar, S. Pooja, S. Kumar, and S. Rajender, "RAD51 135G>C substitution increases breast cancer risk in an ethnic-specific manner: a meta-analysis on 21,236 cases and 19,407 controls," Scientific Reports, vol. 5, no. 11588, pp. 1-10, 2015.

[24] K. Söderlund Leifler, A. Asklid, T. Fornander, and M. Stenmark Askmalm, "The RAD51 135G>C polymorphism is related to the effect of adjuvant therapy in early breast cancer," Journal of Cancer Research and Clinical Oncology, vol. 141, no. 5, pp. 797804, 2015.

[25] S. Franceschi, S. Tomei, C. M. Mazzanti et al., "Association between RAD51 rs1801320 and susceptibility to glioblastoma," Journal of Neuro-Oncology, vol. 126, no. 2, pp. 265-270, 2016.

[26] T. T. H. Trang, H. Nagashima, T. Uchida et al., "RAD51 G135C genetic polymorphism and their potential role in gastric cancer induced by Helicobacter pylori infection in Bhutan," Epidemiology and Infection, vol. 144, no. 2, pp. 234-240, 2016.

[27] B. Mucha, J. Kabzinski, A. Dziki et al., "Polymorphism within the distal RAD51 gene promoter is associated with colorectal cancer in a Polish population," International Journal of Clinical and Experimental Pathology, vol. 8, no. 9, pp. 11601-11607, 2015.

[28] P. Gresner, J. Gromadzinska, K. Polanska, E. Twardowska, J. Jurewicz, and W. Wasowicz, "Genetic variability of Xrcc3 and Rad51 modulates the risk of head and neck cancer," Gene, vol. 504, no. 2, pp. 166-174, 2012.

[29] E.-R. Avadanei, S.-E. Giusca, L. Negura, and I.-D. Caruntu, "Single nucleotide polymorphisms of XRCC3 gene in hepatocellular carcinoma - relationship with clinicopathological features," Polish Journal of Pathology, vol. 69, no. 1, pp. 73-81, 2018.

[30] A. M. Ali, H. Abdulkareem, M. Al Anazi et al., "Polymorphisms in DNA repair gene XRCC3 and susceptibility to breast cancer in saudi females," BioMed Research International, vol. 2016, Article ID 8721052, 9 pages, 2016.
[31] C. Yuan, X. Liu, S. Yan, C. Wang, and B. Kong, "Analyzing association of the XRCC3 gene polymorphism with ovarian cancer risk," BioMed Research International, vol. 2014, Article ID 648137, pp. 1-9, 2014.

[32] R. K. Mandal, R. Kapoor, and R. D. Mittal, "Polymorphic variants of DNA repair gene XRCC3 and XRCC7 and risk of prostate cancer: a study from North Indian population," DNA and Cell Biology, vol. 29, no. 11, pp. 669-674, 2010.

[33] R. D. Mittal, R. Gangwar, R. K. Mandal, P. Srivastava, and D. K. Ahirwar, "Gene variants of XRCC4 and XRCC3 and their association with risk for urothelial bladder cancer," Molecular Biology Reports, vol. 39, no. 2, pp. 1667-1675, 2012.

[34] J. C. Liu, C. W. Tsai, C. M. Hsu et al., "Contribution of double strand break repair gene XRCC3 genotypes to nasopharyngeal carcinoma risk in taiwan," Chinese Journal of Physiology, vol. 58, no. 1, pp. 64-71, 2015.

[35] H. Yang, S. M. Lippman, M. Huang et al., "Genetic polymorphisms in double-strand break DNA repair genes associated with risk of oral premalignant lesions," European Journal of Cancer, vol. 44, no. 11, pp. 1603-1611, 2008.

[36] A. Vral, P. Willems, K. Claes et al., "Combined effect of polymorphisms in Rad51 and XRCC 3 on breast cancer risk and chromosomal radiosensitivity," Molecular Medicine Reports, vol. 4, no. 5, pp. 901-912, 2011. 


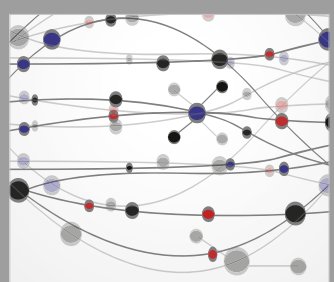

The Scientific World Journal
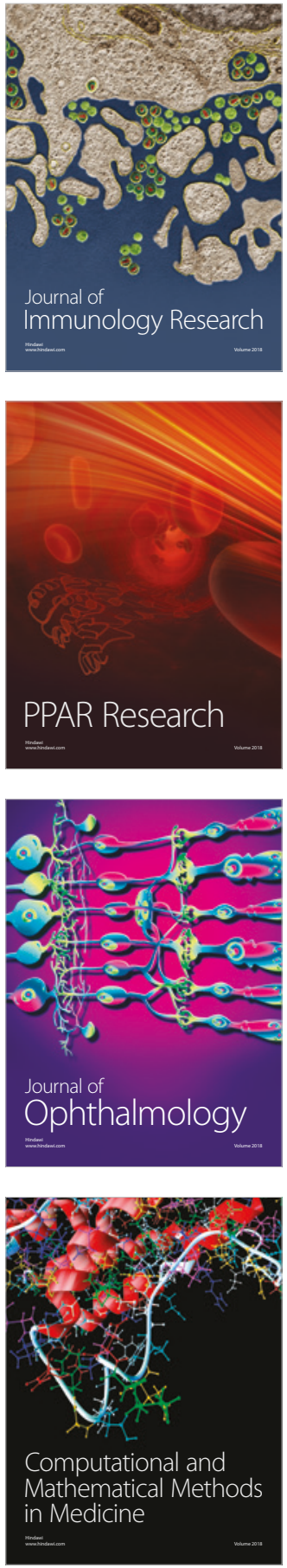

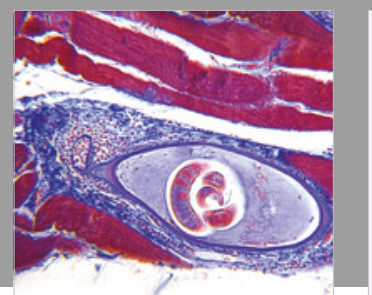

Gastroenterology Research and Practice

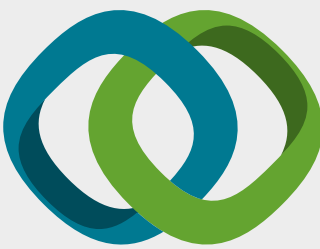

\section{Hindawi}

Submit your manuscripts at

www.hindawi.com
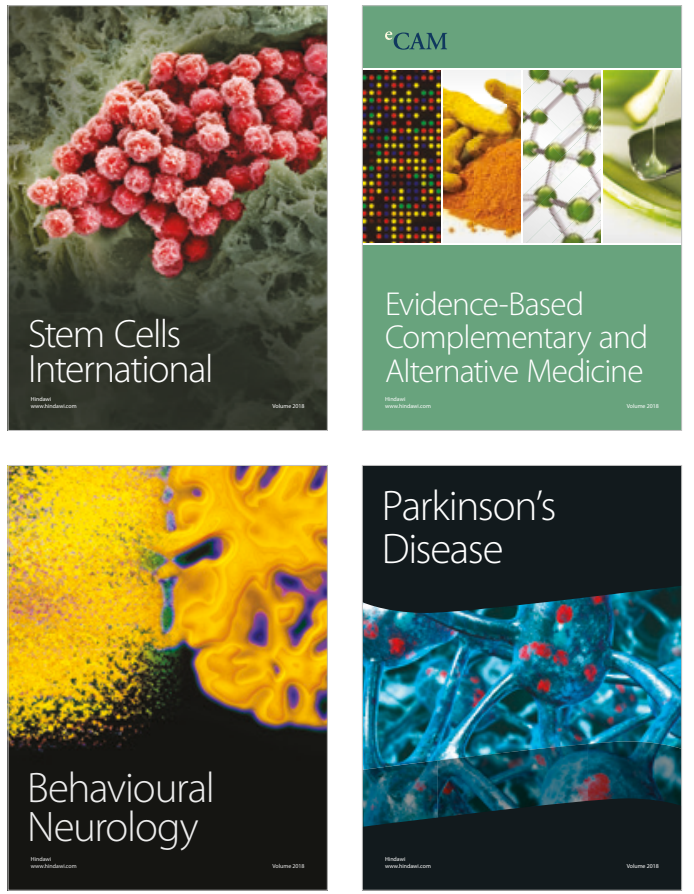

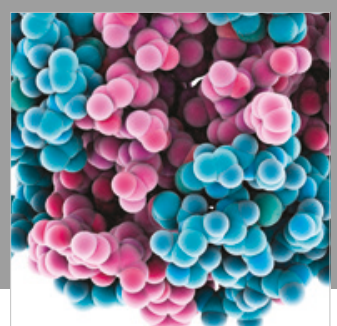

ournal of

Diabetes Research

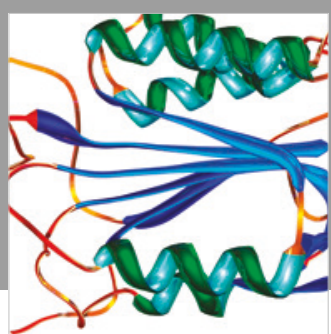

Disease Markers
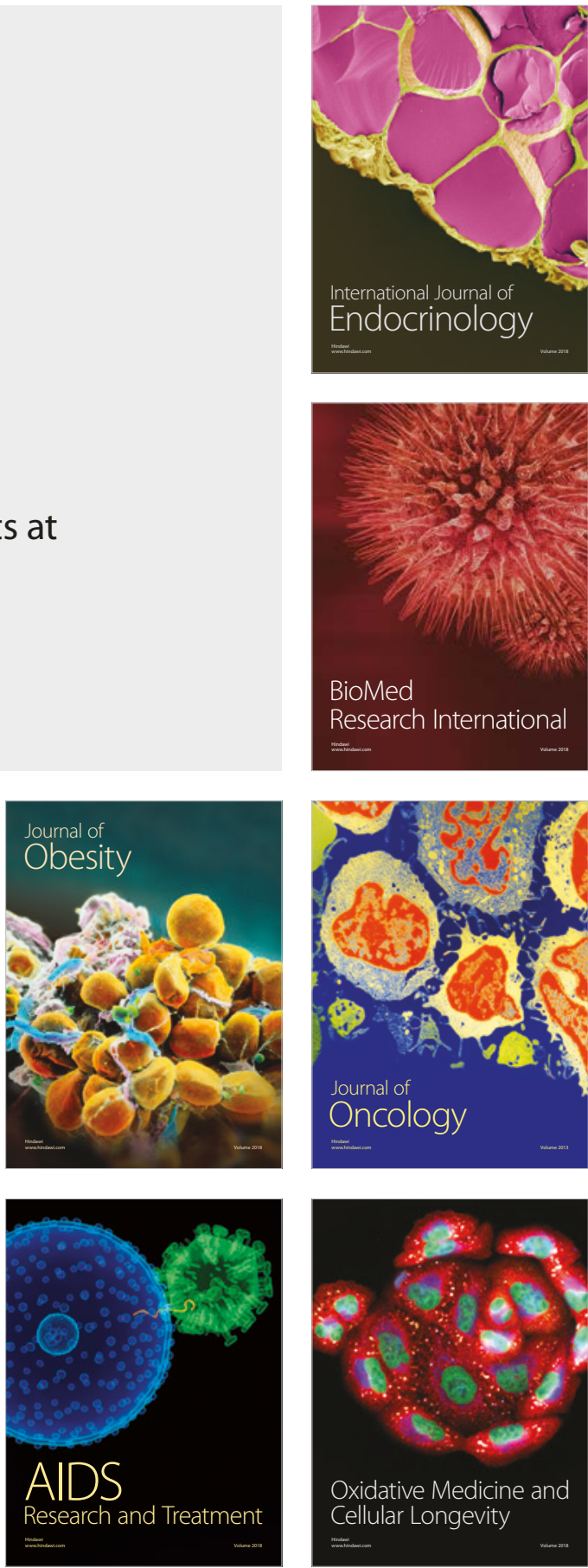